\title{
Release of formaldehyde from polynoxylin and noxythiolin
}

\author{
D. KINGSTON \\ From the Cross-Infection Reference Laboratory, Central Public Health Laboratory, \\ Colindale Avenue, London
}

SYNOPSIS Polynoxylin and noxythiolin (Anaflex and Noxyflex) have been recommended for the $\vec{\infty}$ treatment of certain bacterial infections. Both compounds were shown to release formaldehyde. Detailed studies with noxythiolin showed that it decomposed in solution to liberate most of its 8 formaldehyde, and that solutions of formaldehyde of the appropriate strength gave zones of inhibition on seeded plates comparable in size with those given by noxythiolin. It is suggested that the effects observed with these compounds are caused by the formaldehyde released.

The ability of the urea-formaldehyde polymer polynoxylin to give zones of inhibition on seeded plates was recorded by Brodhage and Stofer (1961) and by Haler and Aebi (1961). Such results are of clinical significance only if the substance responsible for the inhibition is also active at the site of infection, and at the concentrations measured by the test. The chemical structure of polynoxylin made it likely that the agent responsible was formaldehyde, though Haler (1963) considered that this was not so. Polynoxylin is insoluble in water, but the related compound noxythiolin (N-hydroxymethyl-N-methyl-thiourea) is soluble, thus making it easier to work with.

The direct estimation of formaldehyde in solid polynoxylin or in a solution of noxythiolin might itself cause the formaldehyde to be released. Thus it seemed appropriate to estimate the formaldehyde liberated into the vapour phase. Such a technique had already been used in a study of the ability of urea-formaldehyde resins to evolve formaldehyde, and so to render surfaces treated with them selfdisinfecting (Kingston, Lidwell, and Noble, 1962). If a vessel containing water is shut up with another containing noxythiolin solution, the water will adsorb formaldehyde until the vapour pressure of formaldehyde is the same over each solution. When the vapour pressures have come into equilibrium the concentration of formaldehyde in the water will approximate to the concentration of free formaldehyde in the noxythiolin solution. Differences due to the presence in solution of salts, and to a less extent of non-ionic compounds, were shown not to be important in the present study, in part because complete equilibrium was never achieved.

Received for publication 23 November 1964.

\section{METHODS}

Known amounts of the compound, either dry or in $5 \mathrm{ml}$. of solution, were placed in a small beaker with a vessel $\mathscr{\sigma}$ containing $0.5 \mathrm{ml}$. of distilled water alongside. The whole $\mathrm{G}$ was enclosed in a screw-capped unguent jar, $5 \mathrm{~cm}$. in diameter and $4 \frac{1}{2} \mathrm{~cm}$. deep. The cardboard liner had been removed from the lid, and the outside was sealed with Sellotape. After keeping the jars in an incubator at $37^{\circ} \mathrm{C}$. for various periods of time the vessel containing the water 음 was removed and the formaldehyde content estimated $\varrho$ colorimetrically by the method of Nash (1953). Blank $\overrightarrow{\hat{O}}$ determinations were always carried out at the same time 3 from jars containing neither polynoxylin nor noxythiolin. $\vec{T}$

In order to confirm that the gas estimated was in fact formaldehyde, the coloured derivatives were isolated and purified by recrystallization. The absorption spectra of $\overline{0}$ the saturated solutions of these were identical both as to wavelength and as to absorption, whether the derivatives 3 had been prepared from polynoxylin, noxythiolin, or $\delta$ formaldehyde itself.

\section{EXPERIMENTAL OBSERVATIONS}

RELEASE OF FORMALDEHYDE In a preliminary experiment, formaldehyde was found to be evolved $\sigma$ from both products when $0.1 \mathrm{~g}$. of the powder was N held for 18 hours at $37^{\circ} \mathrm{C}$. In this time the noxythiolin N was partially liquefied by the absorption of water $\omega$ vapour and 1-2 $\mathrm{mg}$. formaldehyde was collected from the $0.1 \mathrm{~g}$. of it. Polynoxylin, which remained dry,

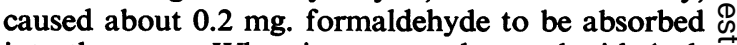
into the water. When it was tested wetted with $1 \mathrm{ml}$. of water, less formaldehyde was transferred, but estimation of the supernatant showed that about $1.5 \mathrm{mg}$. had been released.

More detailed experiments were carried out with 
a $1 \%(\mathrm{w} / \mathrm{v})$ solution of noxythiolin in three $\mathrm{M} / 20$ buffers and, since it has been advocated as a urinarytract disinfectant, in urine. As a check on the efficiency of transfer of formaldehyde to the water, experiments were done in parallel with a $0.2 \%(\mathrm{w} / \mathrm{v})$ formaldehyde solution. (The complete conversion of the hydroxy-methyl group of pure noxythiolin to formaldehyde would have given a $0.25 \%$ solution of formaldehyde.) Unfortunately, complete equilibrium was not achieved even after 40 hours, the concentration in the presence of the formaldehyde solution being a little over half the equilibrium concentration. The concentration of the $0.2 \%$ formaldehyde solution itself was not significantly affected. After the same time, the concentration in the presence of solutions of noxythiolin in buffers of $p \mathrm{H} \mathrm{4}$, 7 , and 10 was $40 \%$ of the equilibrium for complete decomposition, assuming that the compound was pure. Thus it seems that under these conditions the noxythiolin liberates most of its formaldehyde. The concentration of formaldehyde collected from noxythiolin in solution in urine of $p \mathrm{H} 5.5$ was only $15 \%$ of that for equilibrium with completely decomposed noxythiolin. Thus the constituents of urine appeared to reduce the amount of free formaldehyde, presumably by chemical combination.

Another experiment was carried out in which the rate of increase of formaldehyde concentration in the distilled water was compared for noxythiolin in $\mathrm{M} / 20$ phosphate buffer of $p \mathrm{H} 6.25$ and the appropriate concentration of formaldehyde in the same buffer. The mean $p \mathrm{H}$ of urine is 6.25 (Documenta Geigy Scientific Tables, 1962). The noxythiolin solution initially evolved formaldehyde much more slowly than the formaldehyde solution. Thus the liberation of formaldehyde from noxythiolin is not instantaneous, and a solution of this compound will behave differently from a simple solution of formaldehyde. It was also shown that replacing the distilled water by the buffer did not significantly affect the rate of absorption of formaldehyde, so that in these experiments the salt effect is not likely to have been important.

zONES OF INHIBITION The zones of inhibition given by noxythiolin and formaldehyde solutions were compared for several bacteria. Nutrient agar plates were flooded with overnight broth cultures of the organisms diluted $1: 100$ in broth, and the two antiseptics were placed in separate Heatley cups on the same plate. In tests with Staphylococcus aureus and Escherichia coli five drops of a $1 \%(\mathrm{w} / \mathrm{v})$ solution of noxythiolin or of a $0.2 \%(\mathrm{w} / \mathrm{v})$ solution of formaldehyde were put into the cups, corresponding to about $1 \mathrm{mg}$. of noxythiolin and $0.2 \mathrm{mg}$. of formaldehyde. Solutions ten times as strong were used for Pseudo- monas aeruginosa. The zones of inhibition were measured after overnight incubation at $37^{\circ} \mathrm{C}$. Their diameters (in $\mathrm{mm}$.) were as follows, the results with noxythiolin being given first: Staph. aureus, 20, 22; E. coli, 17, 24; Ps. aeruginosa, 28, 32. Thus noxythiolin gives zones similar to those given by comparable amounts of formaldehyde. That the zones are slightly smaller is probably due to the time taken for the noxythiolin to decompose.

\section{DISCUSSION}

These experiments show that broth polynoxylin and noxythiolin release formaldehyde. It seems clear that the formaldehyde released is the cause of the zones of inhibition given by noxythiolin solutions. Enough formaldehyde is released by polynoxylin to make it probable that formaldehyde is the cause of the inhibition zones found with this compound also, though it is difficult to standardize satisfactorily tests with an insoluble powder. It is possible that compounds which slowly release formaldehyde may be useful clinically, but this must be shown by clinical trials, following experiments on the treatment of animal infections. Sensitivity tests in vitro probably merely show that the organism can be inhibited or killed by some concentration of formaldehyde. Promising results have been claimed for polynoxylin used for the treatment of infections of the skin and the ear (Alexander, 1962; Chadwick, 1963), but a properly controlled trial would be necessary to confirm its efficacy. Hexamethylenetetramine, which also decomposes to release formaldehyde and gives zones of inhibition on seeded plates probably due to this (Waterworth, 1962), has been used as a urinary tract disinfectant. The action of such compounds is likely to be non-specific, which is an advantage in that all strains of bacteria are likely to be killed, but a disadvantage in that mammalian cells are likely to be affected also.

We are grateful to Messrs. Geistlich Sons Ltd., Chester, for the gift of supplies of Anaflex (polynoxylin) and Noxyflex (noxythiolin). The absorption spectra were determined by Dr. W. D. Brighton on the recording spectrophotometer at St. Mary's Hospital, by kind permission of Professor Neuberger.

\section{REFERENCES}

Alexander, J. O'D. (1962). Brit. J. Derm., 74, 364.

Brodhage, H., and Stofer, A. R. (1961). Antibiot. and Chemother., 11, 205.

Chadwick, D. L. (1963). Lancet, 2, 1348

Documenta Geigy Scientific Tables (1962). Sixth ed., p. 527. Geigy Pharmaceutical Co. Ltd., Manchester.

Haler, D. (1963). Nature (Lond.), 198, 400.

$\longrightarrow$, and Aebi, A. (1961). Ibid., 190, 734

Kingston, D., Lidwell, O. M., and Noble, W. C. (1962). Mth. Bull. Minist. Hlth Lab. Serv., 21, 246.

Nash, T. (1953). Biochem. J., 55, 416.

Waterworth, P. M. (1962). J. med. Lab. Technol., 19, 163. 